\title{
FORMATION OF POSTSYNAPTIC SPECIALIZATIONS INDUCED BY LATEX BEADS IN CULTURED MUSCLE CELLS ${ }^{1}$
}

\author{
H. BENJAMIN PENG ${ }^{2}$ AND PING-CHIN CHENG
}

Department of Anatomy, University of Illinois College of Medicine, Chicago, Illinois 60680

Received April 5, 1982; Revised June 28, 1982; Accepted June 28, 1982

\begin{abstract}
An early event in the formation of neuromuscular junctions is an accumulation of acetylcholine receptors (AChRs) in the postsynaptic membrane. This concentration of receptors is essential for the establishment of the synaptic transmission. Previously, we showed that latex beads coated with positively charged polypeptide molecules can induce the formation of AChR clusters at the beadmuscle contacts (Peng, H. B., P.-C. Cheng, and P. W. Luther (1981) Nature 292: 831-834). In this study, we demonstrate that, in addition to AChR clusters, a set of postsynaptic specializations normally present at the adult neuromuscular junction also develops at the bead-muscle contacts in the absence of nerve. These specializations include the membrane-associated cytoplasmic density and its associated thin (6- to 8-nm) filaments, clusters of intramembranous particles, membrane invaginations, the basal lamina, and $60-$ to $100-\mathrm{nm}$ coated vesicles. Our results indicate that the mechanism for the formation of the postsynaptic specializations is preprogramed in the muscle and can be triggered by an interaction with polypeptide-coated latex beads. Thus, this bead-muscle system can be used as a simple model for understanding the postsynaptic development during synaptogenesis.
\end{abstract}

Vertebrate nueromuscular junctions (NMJs) usually are associated with elaborate structural specializations within both the presynaptic and postsynaptic elements. Such specializations are thought to be essential for the maintenance of the synaptic transmission. The postsynaptic specializations include clusters of acetylcholine receptors (AChRs) (Fertuck and Salpeter, 1974; Kuffler and Yoshikami, 1975), the basal lamina and its associated cholinesterase (Sanes and Hall, 1979; McMahan et al., 1978), synaptic folds, and cytoplasmic densities underlining the receptor clusters and their associated filaments (Couteaux and Dechavassine, 1968; Hirokawa and Heuser, 1982). These structures develop in response to nerve innervation both in vivo (Hirano, 1967; Teravainen, 1968; Kelly and Zachs, 1969; Kullberg et al., 1977; Weinberg et al., 1981) and in vitro (Pappas et al., 1971; Weldon and Cohen, 1979; Nakajima et al., 1980; Peng et al., 1980). Even in the absence of nerve, the AChR clusters and their associated specializations can develop (Peng and

\footnotetext{
${ }^{1}$ We wish to thank Mrs. Liching Hwang for preparing the tissue cultures and Dr. G. D. Pappas for commenting on the manuscript. This work was supported by National Institutes of Health Grant NS16259 and a grant from the Muscular Dystrophy Association of America.

${ }^{2}$ To whom correspondence should be addressed at Department of Anatomy, University of Illinois College of Medicine, P. O. Box 6998, Chicago, IL 60680
}

Nakajima, 1978; Peng et al., 1980; Yee et al., 1978; Burrage and Lentz, 1981; Moody-Corbett and Cohen, 1981; Weldon et al., 1981). This indicates that the mechanism for the formation of these specializations is preprogramed in the muscle and can be triggered either by an innervating nerve or by certain other exogenous materials. In this latter category, it is known that the culture substrate (Moody-Corbett and Cohen, 1979; Bloch and Geiger, 1980), silk thread (Jones and Vrbova, 1974), basal lamina (Burden et al., 1979; Rubin et al., 1980), and extracts from neuronal tissue (Podleski et al., 1978; Christian et al., 1978; Jessell et al., 1979) all can cause a clustering of AChRs.

The mechanism for the formation of the postsynaptic specializations is not known. Although tissue culture of neurons and muscle cells has provided a useful model in studying the development of these synaptic structures, several experimental difficulties have limited its use. (1) The neurons isolated from the embryonic nervous system are heterogeneous in cell types. Although several types of neurites can make close contacts $(<10 \mathrm{~nm})$ with the muscle, only spinal cord neurons can induce the formation of postsynaptic ultrastructure (Cohen and Weldon, 1980). (2) The optimal culture conditions for neurons and muscle cells are often different. Usually more elaborate conditions are required for the survival of neurons. In performing experimental manipulations designed to 
probe the mechanism that the muscle cell uses to organize the postsynaptic structures (e.g., an alteration of the external ionic milieu), one has to consider not only the survival of muscle cells but also that of the neurons. Thus, the scope of the experiment often is restricted.

Recently, we have provided evidence that the formation of AChR clusters can be induced by polypeptidecoated latex beads in cultured Xenopus muscle cells (Peng et al., 1981a). The receptor clusters are discrete and located exactly at the bead-muscle contacts. The size of the clusters as well as the number of clusters per cell can be controlled simply by using beads of differnt diameter and by altering the concentration of beads applied to the muscle cell. Thus, this "bead-muscle" system may provide a useful model for understanding the development of the postsynaptic membrane specializations. The question is whether other synaptic specializations besides AChR clusters also form.

In this paper, we demonstrate that, indeed, a set of postsynaptic structures associated with mature NMJs develops rapidly at the contacts between polypeptide beads and cultured Xenopus muscle cells concomitantly with the clustering of AChRs. These results indicate that one can use this simple bead-muscle model confidently in elucidating the postsynaptic events during synaptogenesis.

\section{Materials and Methods}

Cell culture. Myotome cells were isolated from stage 20 to 22 Xenopus laevis embryos (Nieuwkoop and Faber, 1967) according to previously described methods (Anderson et al., 1977; Peng and Nakajima, 1978). They were cultured on an appropriate substratum, either glass or plastic coverslips or plastic culture dishes, in Steinberg's solution, consisting of $60 \mathrm{~mm} \mathrm{NaCl}, 0.67 \mathrm{mM} \mathrm{KCl}, 0.34$ $\mathrm{mM} \mathrm{Ca}\left(\mathrm{NO}_{3}\right)_{2}, 0.83 \mathrm{mM} \mathrm{MgSO}$, and $10 \mathrm{~mm}$ 4-(2-hydroxyethyl)-1-piperazine-ethanesulfonic acid (HEPES), pH 7.4 (Jones and Elsdale, 1963; Hamburger, 1960; Peng and Nakajima, 1978), supplemented with 10\% L-15 (Leibovitz) medium and $1 \%$ fetal bovine serum (Gibco, Grand Island, NY). The cultures were maintained at $22^{\circ} \mathrm{C}$.

Preparation of latex beads. Polystyrene latex beads, with a diameter ranging from 1.2 to $6 \mu \mathrm{m}$, were purchased from Polysciences (Warrington, PA). They were incubated with $1 \mathrm{mg} / \mathrm{ml}$ of poly-L-lysine $\left(M_{\mathrm{r}}=3,000\right.$; Sigma) or poly-L- $\alpha$-ornithine $\left(M_{\mathrm{r}}=30,000\right.$; Sigma) dissolved in phosphate-buffered saline (PBS) overnight at $4^{\circ} \mathrm{C}$. Then the beads were washed extensively with $\mathrm{PBS}$ by repeated centrifugation and resuspension using a microcentrifuge. These beads were stored in PBS at $4^{\circ} \mathrm{C}$ for up to 4 weeks. Polypeptide-coated beads tend to clump. The large clumps can be dispersed by brief sonication just prior to use.

To attach the beads to cultured cells, a few drops of the beads were applied to each culture at 1 week of age and, after the beads settled down (in about $5 \mathrm{~min}$ ), excess beads were washed off with culture medium and the culture was allowed to develop further. The concentration of the bead suspension applied to the culture was adjusted so that, on the average, each cell is contacted by 5 to 10 beads. This concentration allows sufficient $\mathrm{AChR}$ clusters to form on each cell without overcrowding the cell surface area. Uncoated beads were used as controls.

Visualization of AChR clusters. To visualize the AChR clusters, the culture was first labeled with tetramethylrhodamine-conjugated $\alpha$-bungarotoxin (R-BTX) in the living state (Anderson et al., 1977; Ravdin and Axelrod, 1977). After washing the excess toxin off, the culture was mounted for live observation or fixed with $95 \%$ ethyl alcohol at $-20^{\circ} \mathrm{C}$ for $3 \mathrm{~min}$ followed by a PBS wash and mounting with a mixture of $35 \%$ glycerol (v/v) and $20 \%$ polyvinyl alcohol (w/v) in PBS, $\mathrm{pH} 7.2$ (Rodriguez and Deinhardt, 1960). The location of the AChR clusters, as evidenced by R-BTX fluorescence, was determined by fluorescence microscopy using a Leitz Orthoplan microscope equipped with an epifluorescent illuminator with filter cube N2.1 and a $\times 40$ (numerical aperture, 1.3) objective. The location of the cluster in relation to the cell and its association with beads were assayed by a combination of phase contrast and fluorescence microscopy. The images were photographed with an Olympus OM-2N camera using Kodak Tri-X film, developed in D-76 developer (full strength) for $10 \mathrm{~min}$ at $20^{\circ} \mathrm{C}$.

For live observation, the culture coverslip was supported by two strips of No. 2 cover glass with the cell face down on a slide. The edges of such a wet chamber were sealed with dental wax. The cells remain viable for several hours under this condition. The culture can be removed later for electron microscopy following light microscopic observation.

Thin section. The cells were fixed in situ with $0.5 \%$ glutaraldehyde in $0.05 \mathrm{M}$ cacodylate buffer $(\mathrm{pH} 7.2)$ or with a mixture of $1.5 \%$ glutaraldehyde, $0.5 \%$ paraformaldehyde, and $0.7 \%$ acrolein in the same buffer for $2 \mathrm{hr}$. The lower aldehyde concentration enabled us to see the cytoskeletal structures with clarity but often resulted in an extraction of the ground cytoplasm. The higher aldehyde concentration, on the other hand, rendered good fixation but often obscured the visualization of cytoplasmic filaments. Most of the data reported here were done with the former fixative. After aldehyde fixation, the culture was postfixed with $1 \% \mathrm{OsO}_{4}$ in the same buffer, stained en bloc with $1 \%$ uranyl acetate in $50 \mathrm{~mm}$ acetate buffer ( $\mathrm{pH} 5.5$ ), dehydrated through an ethanol series, and embedded in Epon 812. After removing the block from the original substratum, selected cells were cut out and semiserially thin-sectioned perpendicular to the substrate with a diamond knife on an American Optical Ultracut microtome. The sections were mounted on Formvar-coated single slot grids (Ted Pella, Tustin, CA) according to the method of Cheng and Lin (1981), stained with uranyl acetate and lead citrate, and examined with a JEOL $100 \mathrm{~S}$ electron microscope at 80 and $100 \mathrm{kV}$.

To study identified cells, the culture was prepared on polystyrene coverslips (Lux, Newbury Park, CA). The AChR clusters were identified with fluorescent and phase microscopy in the living state and the cells were photographed at both high and low magnifications to facilitate later identification under EM. After embedding, the cell was cut in serial sections and its bead-muscle contacts which were associated with R-BTX fluorescence could be identified by careful comparison between the light 
and low power EM micrographs (Figs. 6 and 7). The thin section data reported here were collected from more than 30 cells in seven separate experiments.

Freeze-fracture. Cells were plated on 4-mm No. 0 cover glass circles. After bead-muscle co-culture, they were fixed with $0.5 \%$ glutaraldehyde in $0.05 \mathrm{M}$ cacodylate buffer, treated with $30 \%$ glycerol in buffer and freezefractured according to previously described methods (Yee et al., 1978; Peng and Nakajima, 1978). The replicas also were mounted on single slot grids and examined under EM. The muscle cells were identified by previously described criteria (Peng and Nakajima, 1978).

Scanning electron microscopy. The cells were fixed with $3 \%$ glutaraldehyde and $4 \%$ tannic acid followed by $1 \% \mathrm{OsO}_{4}$, dehydrated through ethyl alcohol, criticalpoint-dried through $\mathrm{CO}_{2}$, coated with platinum/palladium, and viewed with a JEOL $35 \mathrm{C}$ scanning electron microscope at the secondary electron emission mode.

Whole mount. The cells were plated on Formvarcoated gold finder grids according to previously described methods (Wolosewick and Porter, 1979). After a period of bead-muscle co-culture, the grids were fixed, dehydrated, and critical-point-dried (Peng et al., 1981b). Stereo images of bead-muscle contacts in areas of the cell sufficiently thin for imaging were taken with a JEOL $100 \mathrm{CX}$ electron microscope with a side entry goniometer stage at $100 \mathrm{kV}$. The stereo micrograph (Fig. 19) can be viewed with a stereoscopic binocular lens.

\section{Results}

AChR clusters. Previously, we showed that 1- $\mu \mathrm{m}$ polylysine-coated beads can induce the formation of AChR clusters with a diameter of $1 \mu \mathrm{m}$ or smaller (Peng et al., 1981a). We found that, when $6-\mu \mathrm{m}$ polyornithine-coated beads were used, clusters as large as $5 \mu \mathrm{m}$ in diameter were generated (Fig. 1, $a$ and $b$ ). These clusters are discrete and localized exactly at the bead-muscle contacts on the top or the edge of the cell. They are absent from the bottom of the cell, where the beads are excluded due to the narrowness of the space between the cell and the substrate. In these large clusters, a distinct fine structure can be recognized; each cluster usually is composed of smaller subunits ( 1 to 5 in Fig. $1 b$ ). This pattern corresponds well with the pattern of the intramembranous particles as revealed by the freeze-fracture procedure described below. In cultures preincubated with native $\alpha$-BTX ( $\alpha$-bungarotoxin) followed by R-BTX, the rhodamine fluorescence is suppressed completely (Fig. 1, $e$ and $f$ ), and no specific fluorescence is associated with bead-cell contacts in nonmuscle cells (Fig. $1, g$ and $h$ ). Uncoated beads have no effects on the distribution of AChR clusters (Fig. 1, $c$ and $d$ ). The clusters existing in the noncontact areas are similar to those found in cultures without bead treatment.

In light microscopic studies, we found that AChR clusters are formed at an average of $70 \%$ of the polyornithine bead-muscle contacts ( $n=13$; range, $50 \%$ to $95 \%$ ). Freshly prepared beads consistently showed stronger effects. Scanning electron micrographs (Fig. 2) indicate that there are two kinds of contacts: either the bead makes a very close contact with the cell so as to give a "sink-in" appearance or it sits entirely on the surface.
Our thin section and whole mount studies have shown that all AChR cluster-positive contacts belong to the first type (described below). Thus, perhaps the superficial type of contact fails to induce AChR clusters.

Old versus new receptors. To determine whether the existing AChRs on the cell surface are recruited into the formation of bead-induced clusters, we labeled the cells with R-BTX prior to the addition of beads and then examined the cells live after an overnight bead-muscle co-culture. As shown in Figure 3, $a$ and $b$, R-BTX fluorescence is clearly associated with the beads, thus indicating that the existing receptors contribute to the formation of new clusters. On the other hand, if we labeled the cells with native $\alpha$-BTX prior to the addition of beads and then assayed the AChR clusters with R-BTX following an overnight bead-muscle co-culture, fluorescence also was detected at the bead-muscle contacts (Fig. 3, c and $d$ ). This indicates that receptors inserted into the membrane after the addition of beads also contribute to the formation of new clusters. Thus, it seems that both old and new receptors are utilized in the formation of clusters at the bead-muscle contacts.

To quantitate this observation, we scored the percentage of bead-muscle contacts which are AChR clusterpositive after these two types of treatment. The results are summarized in Table I. In the control, the cultures were treated with the beads and then assayed for $\mathrm{AChR}$ clusters with R-BTX. Thus, both the AChRs existent in the surface membrane and the newly inserted receptors are assayed. In the test cultures, the cells were prelabeled either with R-BTX (experiment 1 in Table I) or with native $\alpha$-BTX (experiment 2 in Table I) before the addition of beads and then assayed for AChR clusters induced by the beads. In the former case, the contribution of existent surface receptors is assayed, and in the latter case, the contribution of the receptors inserted into the membrane after the addition of beads is assayed. Our results shown in Table I indicate that both categories of receptors contribute to about $90 \%$ of the new clusters induced by the beads. Thus, these results also indicate that both pools of receptors are utilized in the formation of new clusters.

Freeze-fracture. The bead-muscle contacts can be visualized in freeze-fracture replicas as 2- to $5-\mu \mathrm{m}$ round protoplasmic face (P face) depressions (Fig. 4) and corresponding exoplasmic face ( $\mathrm{E}$ face) protuberances when $6-\mu \mathrm{m}$ beads are used. Inside of these $\mathrm{P}$ face depressions, large (11- to $12-\mathrm{nm}$ ) intramembranous particles are organized into aggregates ranging from less than $0.1 \mu \mathrm{m}$ (comprised of only a few particles) to $0.5 \mu \mathrm{m}$ in width (Fig. 5). The membrane area where these particles are aggregated has a slightly bulged appearance as compared to the relatively smooth appearance of the particle-poor membrane. Between adjacent particle aggregates is an area nearly devoid of these large particles. The boundary within which these particle aggregates exist is well defined (Fig. 5); few aggregates are observed outside of the bead-muscle contact. Within the contact, however, considerable heterogeneity in the distribution of these particle aggregates is seen. They range from a uniform distribution within the center of the contact to a concentration to one side or along the rim of the contact. The 

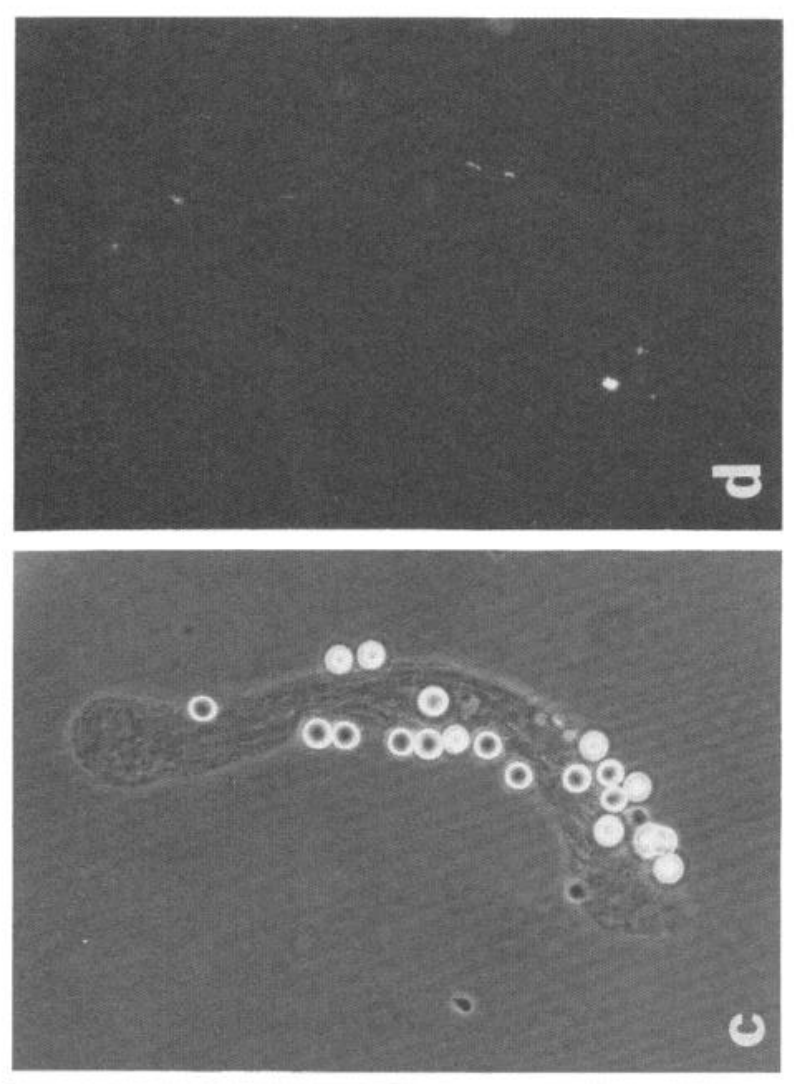

3
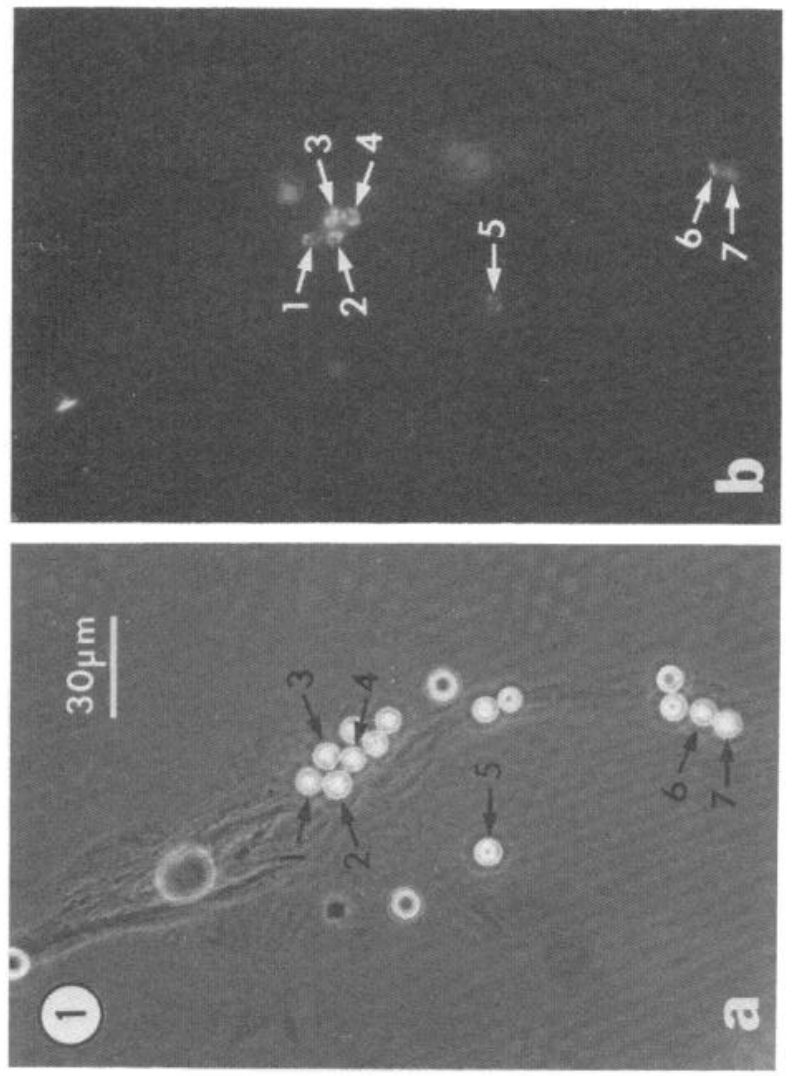
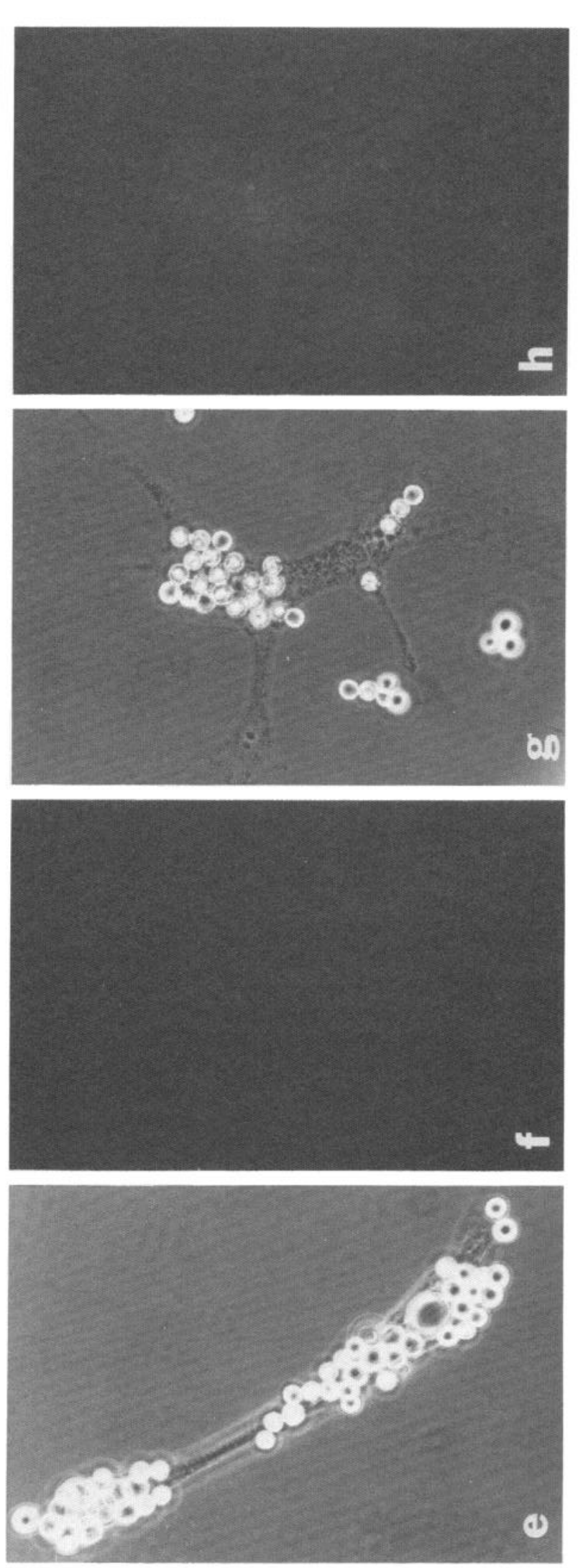

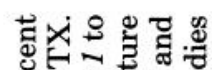

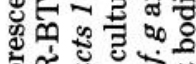

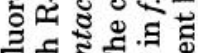

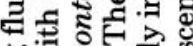

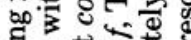
至 0

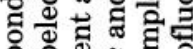
की

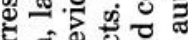
o. . .

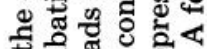

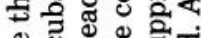

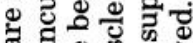

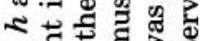

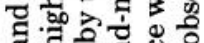
$\leftrightarrow$ ช

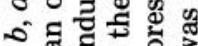

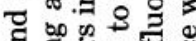
वै की s 우ㅇㅡㅡㄹ 른 웅 $x$ 둑 웡 두워 สี की 요 政击它

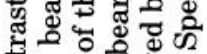
두워 의 룽훙 o 의 담 ․ㅖㄹ क 곤 on 을 可. का $x$. $x$ ० ०. $03 \frac{\pi}{2}$

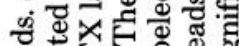
\% \&ั × 几 एँ ซึ

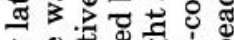
>

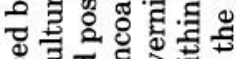
ฮั उु

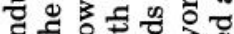
द्य कू

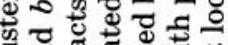

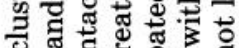
ح 0 용 ด

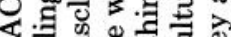

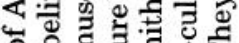
国

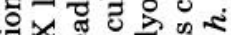
牙公 है 둥

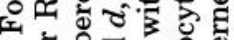

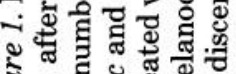
:

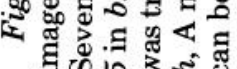




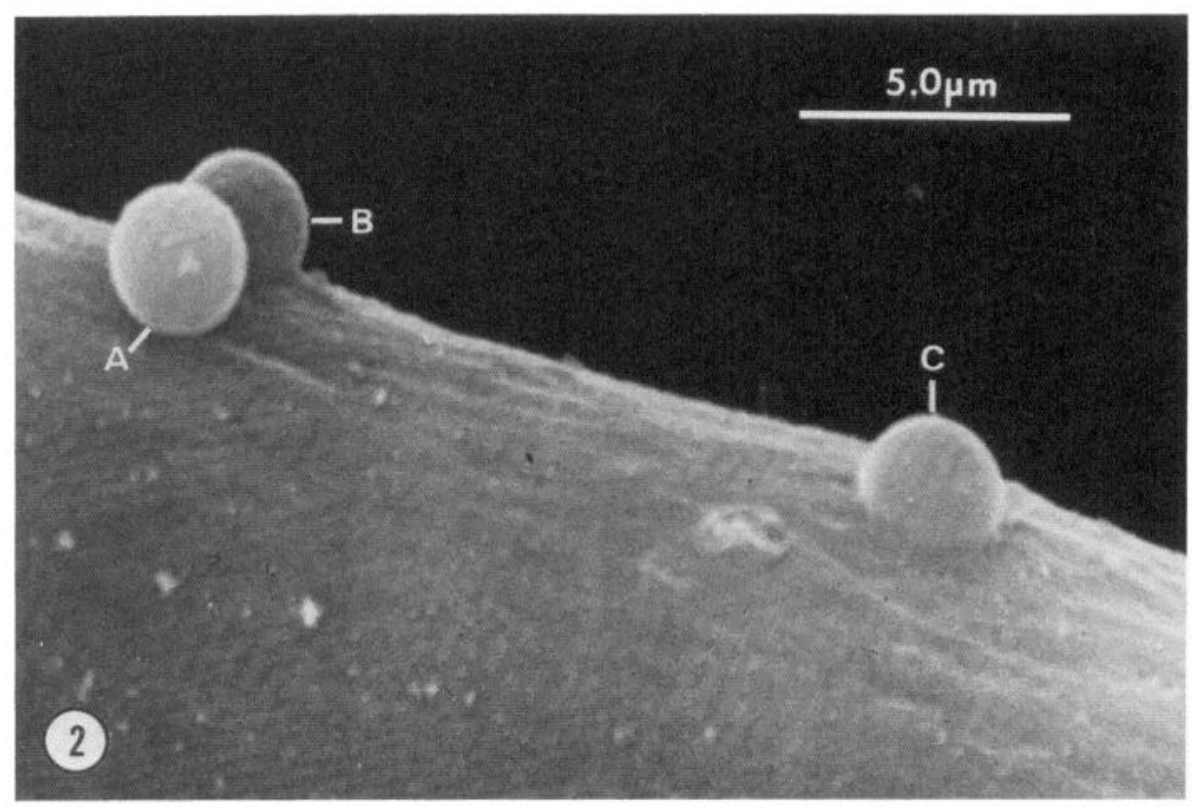

Figure 2. Scanning electron micrograph of the contacts between polyornithine-coated beads and the muscle cell. Two types of contacts, a superficial type $(A)$ and an intimate or "sink-in" type ( $B$ and $C$ ), can be seen at the cell surface of this 1-day bead-muscle co-culture. Magnification $\times 5,400$.

arrangement of the particles into aggregates and their distribution correspond well with the light microscopic pattern of AChR clusters at the bead-muscle contacts. Thus, these particle aggregates presumably indicate the positions of clustered AChRs. Particle aggregates were absent in about $10 \%$ of the $\mathrm{P}$ face depressions made by the beads. These depressions were usually shallower than the aggregate-positive ones.

Invaginations of the surface membrane, as indicated by cross-fractures through the extracellular ice (Fig. 5), are also prominent within the bead-muscle contacts. These invaginations (or folds), irregular in shape and having a width of 0.1 to $0.5 \mu \mathrm{m}$, were observed previously at developing AChR clusters in young cell cultures 1 to 2 days old (Peng et al., 1980). They represent an inward pocketing of the surface membrane as shown in thin sections (Figs. 10 and 11). The rim of the invagination usually is associated with aggregates of large intramembranous particles (Fig. 5).

Thin section. In most studies, sections were made at bead-muscle contacts, where AChR clusters had been identified in the living state with R-BTX staining. One such correlation between light and electron microscopy is shown in Figures 6 and 7 . All thin section data presented here, with the exception of Figure 8, were taken from contacts identified as AChR cluster-positive. The polyornithine-coated beads usually made close contacts with the muscle cells such that the beads partially sank into the depression created at the cell surface (Fig. 6), corresponding to their scanning electron microscopic appearance (Fig. 2). The cell sometimes sends up short processes to wrap around the beads (Fig. 6), although internalization of the beads has never been observed. The separation between these beads and the cell membrane is usually less than $20 \mathrm{~nm}$ (Fig. 8) in contrast to the contact between the untreated bead and the muscle cell which generally has a gap of more than $50 \mathrm{~nm}$ (Fig. 16). On the surface of coated beads, globular structures 15 to $20 \mathrm{~nm}$ in diameter are observed (Figs. 10 to 12, and 14). These are absent from the surface of uncoated beads (Figs. 16 and 17). Thus, the globules probably represent polyornithine or certain components in the medium adsorbed onto the beads. They often span the entire gap between the bead and the cell.

Membrane-associated density. Cytoplasmic density closely associated with the membrane is observed at the polyornithine bead-muscle contact (Fig. 8). This density has a thickness of 20 to $30 \mathrm{~nm}$ and usually is separated into patches 0.1 to $0.5 \mu \mathrm{m}$ in length. The membrane with its underlining density often shows a gentle convolution (Fig. 8) characteristic of AChR clusters in these muscle cells not treated with beads (Peng et al., 1980; Kullberg et al., 1977). Such a fragmented appearance of the density also corresponds well with the fine structure of beadinduced AChR clusters evident in light microscopy (Fig. $1 a)$.

The density often is connected with 6- to 8-nm filaments as shown in Figure 9. In whole mount studies to be described later, it is clear that these filaments belong to the bundles of thin filaments which seem to converge to the bead-muscle contact (Fig. 19). Electron-dense particles about $13 \mathrm{~nm}$ in diameter often are associated with the membrane at the contact area (Figs. 9, inset and 12). The center-to-center spacing between these particles ranges from 12 to $20 \mathrm{~nm}$. They project into the cytoplasm and their cytoplasmic end usually is associated with a short segment of 3- to 5-nm filament (Fig. 9, inset). Microtubules frequently are observed in this area (Fig. 9 ), but we do not know yet whether they are concentrated there.

Membrane invaginations. Invaginations of the surface membrane often are observed at the bead-muscle con- 

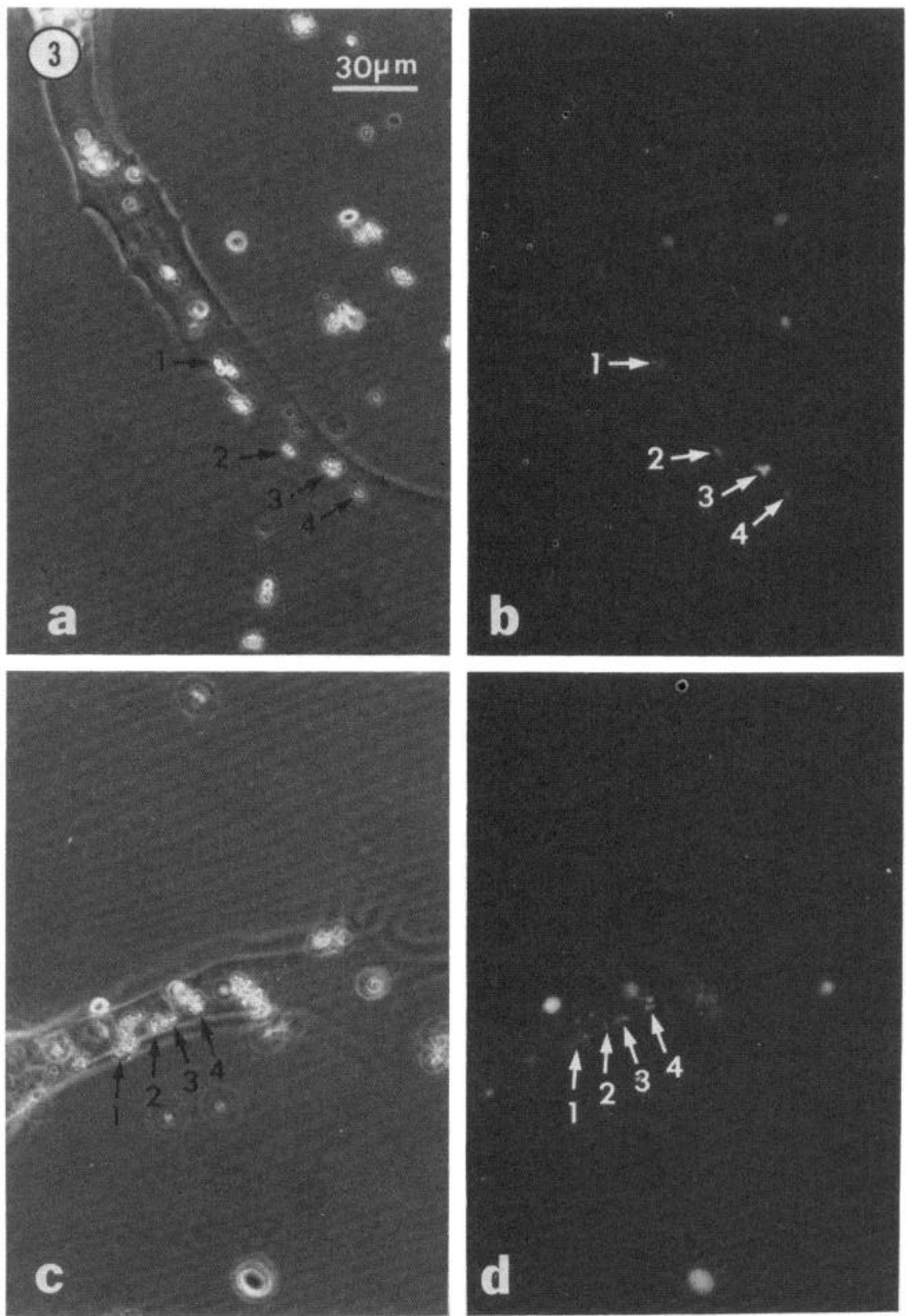

Figure 3. Existing versus newly inserted AChRs. $a$ and $b$, The culture was first labeled with R-BTX and then treated with $1.2-\mu \mathrm{m}$ polyornithine-coated beads. After an overnight incubation, the culture was mounted for live observation. The numbers indicate correspondence between the phase contrast images of the beadmuscle contacts $(a)$ and R-BTX fluorescence $(b)$. This shows that existing AChRs were recruited to the contacts to form the new clusters. $c$ and $d$, The culture was first labeled with native $\beta$-BTX and then treated with polyornithine beads. Following an overnight incubation, it was labeled with R-BTX and observed alive. Correspondence between the contacts $(c)$ and the R-BTX fluorescence $(d)$ indicates that new receptors inserted into the cell surface after the addition of beads also contributed to the formation of new clusters. Magnification $\times 350$.

tacts (Figs. 10 and 11). They are irregular in shape, with an opening of 0.1 to $0.5 \mu \mathrm{m}$, and extend from 0.1 to more than $1 \mu \mathrm{m}$ into the cell. Because of their irregularity, some invaginations appear to be within the cell (Fig. 13), probably cut off from the cell surface during sectioning. The membrane of the invagination usually is lined with a cytoplasmic density and often is associated with thin filaments (Figs. 11 to 13). The fragmented appearance of the cytoplasmic density, characteristic of the surface membrane (Fig. 8), also can be detected along the invagination (Fig. 12). The localization of these folds at the bead-muscle contact and their opening size correspond well with their freeze-fracture images (Fig. 5).

Basal lamina. Because of the close apposition between the bead and the muscle, it is difficult to judge morphologically whether extracellular material has accumulated at the intimate contact. However, in areas where the beads are separated farther from the membrane (e.g., 
TABLE I

Contribution of the membrane pool and the intracellular pool of AChRs to the formation of clusters induced by latex beads

AChR clusters were induced by applying 4- $\mu \mathrm{m}$ polyornithinecoated beads to muscle cultures 1 week of age. In the control of each experiment, the beads were applied first and, following an overnight bead-muscle co-culture, the cells were labeled with R-BTX and processed for fluorescence microscopy.

\begin{tabular}{clcc}
$\begin{array}{c}\text { Experi- } \\
\text { ment }\end{array}$ & \multicolumn{1}{c}{ Procedure } & $\begin{array}{c}\text { Bead-Muscle Contacts } \\
\text { Associated with AChR } \\
\text { Clusters }\end{array}$ & $\begin{array}{c}\text { Ratio: } \\
\text { Test/Control }\end{array}$ \\
\hline & & \multicolumn{1}{c}{$\%$} & \\
1 & Control & $81.8 \pm 3.4(20 ; 165)$ & 0.88 \\
& $\begin{array}{l}\text { Prelabeled with } \\
\text { R-BTX }\end{array}$ & $72.1 \pm 3.0(20 ; 229)$ & \\
& & & \\
2 & Control & $83.5 \pm 3.9(20 ; 140)$ & 0.86 \\
& $\begin{array}{c}\text { Prelabeled with } \\
\text { native } \alpha \text {-BTX }\end{array}$ & $71.5 \pm 5.7(10 ; 81)$ & \\
& &
\end{tabular}

${ }^{a}$ The values are expressed as the mean \pm SEM. Given in parentheses are the number of cells scored and the total number of bead-muscle contacts scored. The cells were selected randomly and every beadmuscle contact in each cell was scored.

${ }^{b}$ The culture was first labeled with R-BTX and then the beads were added. After an overnight bead-muscle co-culture, it was processed for fluorescence microscopy without additional labeling.

"The culture was first labeled with native $\alpha$-BTX and then the beads were added. After an overnight head-muscle co-culture, it was labeled with R-BTX and processed for fluorescence microscopy.

within an invagination), a distinctive basal lamina can be observed within the cleft (Figs. 11, 12 and 14). In sections, it appears as an electron-dense band spaced at a uniform distance from the membrane. Connections between the basal lamina and the membrane often can be observed (Fig. 11). Certain other extracellular fibrils, 10 to $15 \mathrm{~nm}$ thick, also can be observed within the cleft (Figs. 12 to 14). These fibrils appear not to be in close association with the membrane.

Coated vesicles. Coated vesicles, with a diameter of 60 to $100 \mathrm{~nm}$, often are observed in the cytoplasm close to the bead-muscle contact (Fig. 15, $a$ and $b$ ). The coat of these vesicle consists of equally spaced electron-dense particles, 13 to $15 \mathrm{~nm}$ in diameter, which project into the cytoplasm (Fig. 15b). Coated pits, $100 \mathrm{~nm}$ in diameter, also can be observed at the bead-muscle contact (Fig. $15 c)$. At present, we do not know whether these structures are especially concentrated at the contact.

Controls. The aforementioned thin section specializations were observed only at the contact area between the polyornithine bead and the cell. Immediately lateral to the contact, the cytoplasm becomes indistinguishable from the rest of the cell. As a further control, we also have studied the contacts beween uncoated beads and the muscle cell. These contacts are characterized by a gap of about $50 \mathrm{~nm}$ or larger (Fig. 16). Within the cleft, electron-dense material in close association with the cell surface also can be detected (Fig. 16). This cleft material has a loose granular appearance (Fig. 17) different from the linear band appearance between the polyornithine bead and the muscle cell (Figs. 11, 12, and 14). However, 10- to 15-nm-thick fibrils, not in association with the membrane and similar to those seen in Figures 12 to 14, also are observed in the cleft between uncoated beads and the muscle cell (Fig. 17). Occasionally, the membrane in the contact area also shows an increased density and a slight convolution (Fig. 17). However, other specializations, including the cytoplasmic density with its associated thin filaments and the membrane invaginations, are absent. The cytoplasm in the contact area is occupied by organelles which normally are seen throughout the muscle cell, including polysomes, smooth and rough endoplasmic reticulum, and mitochondria (Fig. 16), whereas these structures usually are excluded from the area underneath the contact between the polyornithine bead and the muscle cell.

Basal lamina, similar to the cleft material shown in Figure 17, also is observed in areas of the cell away from the beads. Its coverage usually is restricted to patches of the membrane. The bulk of the membrane generally has very little extracellular covering.

Thin filaments and whole mount studies. As we have described above, the density at the polyornithine beadmuscle contact often is associated with 6- to 8-nm thin filaments. Bundles of thin filaments, running the entire length of the cell, often are observed in these muscle cells in addition to the differentiated myofibrils (Peng et al., 1981b). As Figure 18 shows, a loose bundle of thin filaments seems to attach to the membrane at the contact. Often, the thin filaments associated with the contact actually come from a differentiated myofibril (Fig. 13).

The disposition of the thin filaments can best be demonstrated with the whole mount technique. Figure 19 shows in stereo a very close bead-muscle contact in an area of the cell sufficiently thin for whole mount observation. A bundle of 6 - to $8-\mathrm{nm}$ thin filaments (between the arrowheads in Fig. 19) lies along the cell margin both above and below the bead. However, when the filaments reach the bead-muscle contact, they seem to change their course and become attached to the membrane at the contact area. Such association between thin filaments and the membrane at the contact seems analogous to the thin section image shown in Figure 18.

\section{Discussion}

In this study, we have demonstrated, with light and electron microscopy, the formation of specializations characteristic of the postsynaptic membrane at the contacts between polypeptide-coated latex beads and cultured Xenopus muscle cells. These specializations include clusters of AChRs and their associaled intramembranous particles, membrane invaginations, basal lamina, and cytoplasmic density and its associated thin filaments. The formation of these specializations in the complete absence of nerve has been reported previously by various investigators. For example, the formation of AChR clusters, or hot spots, in the absence of nerve has long been known (Fischbach and Cohen, 1973; Sytkowski et al., 1973; Anderson et al., 1977) as have some of the specializations on the electron microscopic level described here (Peng and Nakajima, 1978; Peng et al., 1980; Weldon et al., 1981; Yee et al., 1978; Cohen and Pumplin, 1979). However, the most significant aspect of this work is that we can induce these specializations specifically at the bead-muscle contacts. This simple technique may greatly facilitate the understanding of the cellular mechanisms 

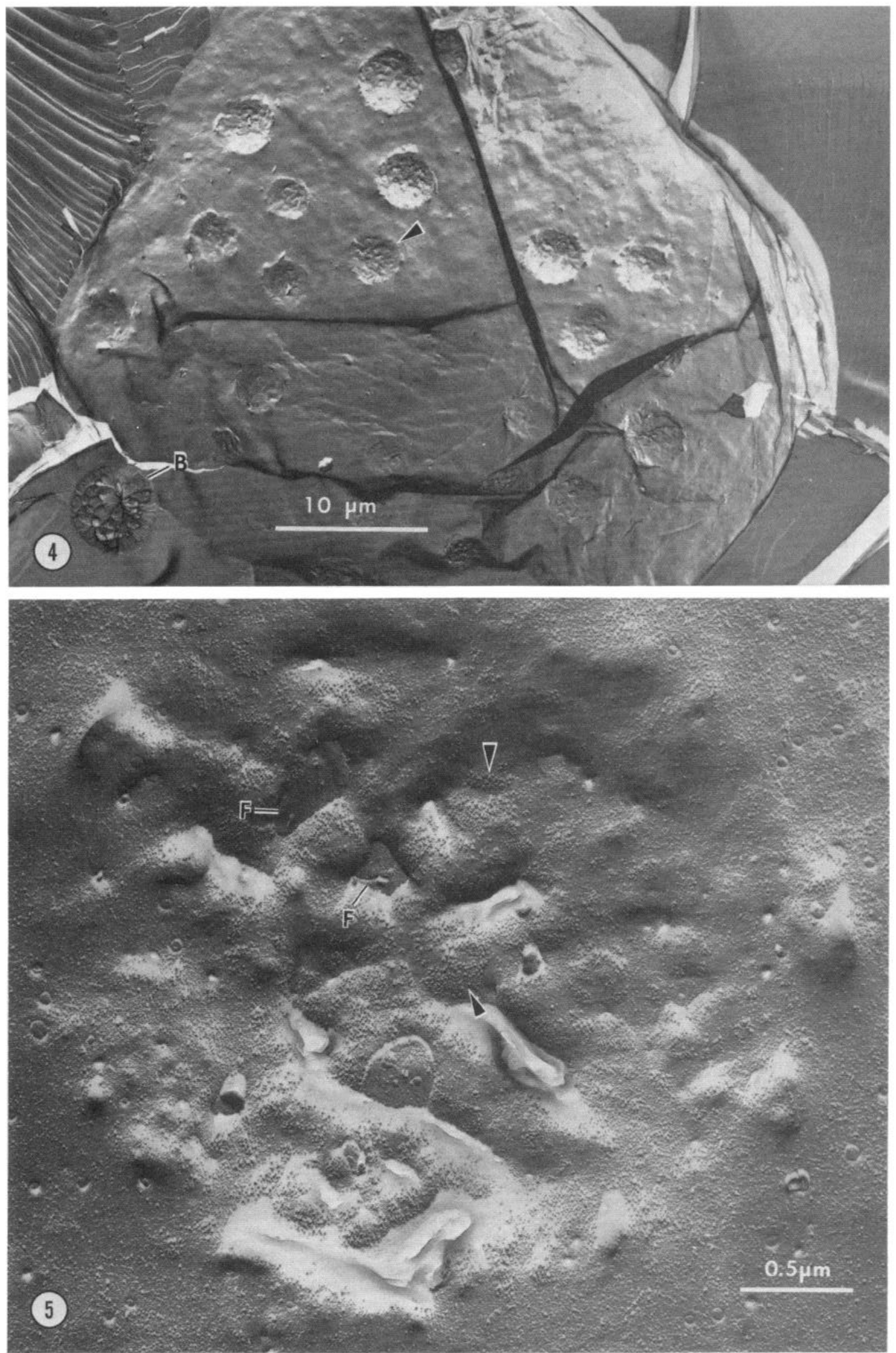

Figure 4. Freeze-fracture image of polyornithine bead-muscle contacts. The protoplasmic face (P face) is shown. These contacts appear as round depressions. The arrowhead points to a depression which is enlarged in Figure 5 . A cross-fractured bead $(B)$ also is seen in this 2-day bead-muscle co-culture. Magnification $\times 2,600$.

Figure 5. Clusters of intramembranous particles. This is an enlarged view of the area marked by the arrowhead in Figure 4. Aggregates of large (11- to 12-nm) intramembranous particles (arrowheads) are confined within the depression created by the bead. Aggregates are separated from each other by grooves devoid of these large particles. Several membrane invaginations $(F)$ are also obvious. At these places, the fracture plane could not follow the curvature of the membrane and thus traveled through the ice. Magnification $\times 38,450$. 

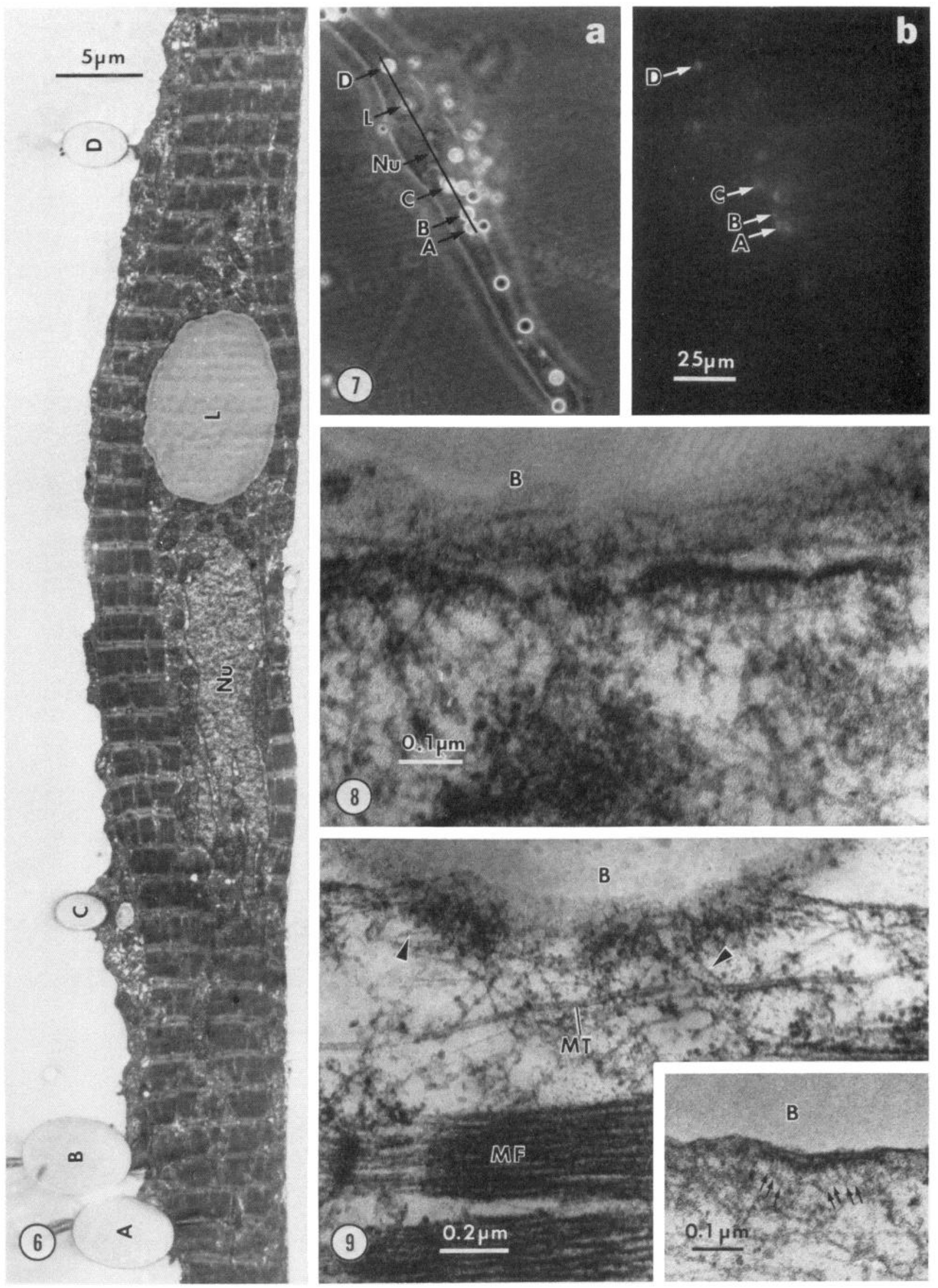
involved in the formation of the postsynaptic membrane. Closely related to our work is the finding that presynaptic specializations, including the membrane-associated cytoplasmic density and the clumping of synaptic vesicles, can be induced at the contacts between positively charged Sepharose beads and the neurites from cultured rat cerebellum neurons (Burry, 1980). Thus, this local membrane perturbation mediated by charged beads is also a useful tool for studying the presynaptic development.

At present, we do not understand why the latex beads can induce these specializations. Since the bead-induced clustering of AChRs can proceed in Steinberg's solution consisting of inorganic ions only (H. B. Peng, unpublished data), it is unlikely that these beads act by collecting and concentrating macromolecular components in the medium. Our recent evidence (H. B. Peng and P. W. Luther, manuscript in preparation) has indicated that this beadinduced AChR clustering can be suppressed by calcium antagonists or inhibitors against calmodulin. Thus, these polypeptide-coated beads may act by triggering a calcium-mediated event.

Association of thin filaments. Our thin section and whole mount studies have clearly shown an association between thin filaments and the area of the membrane where AChRs are clustered at the bead-muscle contacts. Since these filaments are often a direct extension of the thin filaments from a myofibril (Fig. 13), they probably are composed of actin. Recently, Hall et al. (1981) have shown that cytoplasmic actin is concentrated at the postsynaptic membrane. Our data thus suggest that the actin molecules in this area might be organized into filaments during the formation of $\mathrm{AChR}$ clusters.

In our previous study on the development of myofibrils (Peng et al., 1981b), we demonstrated the existence of bundles of thin (actin) filaments, similar to the stress fibers in nonmuscle cells, in these cultured Xenopus myotomal cells. They seem to serve as precursors for the myofibrils. These filament bundles often are associated with the cell cortex and the cell margin. At the beadinduced AChR clusters, these actin filaments seem to become associated with the membrane at the bead-muscle contact (Figs. 18 and 19). This may suggest that the association of these thin filaments with the cell membrane changes from a lateral configuration prior to the contact with the bead to an end-on configuration after the contact. Such an end-on association beween the thin filaments and the membrane also is observed at the coated membrane during receptor-mediated endocytosis (Salisbury et al,, 1980). Recent evidence has shown that vinculin, a peripheral membrane protein, may mediate such an end-on association of actin filaments with the plasma membrane (Geiger, 1979; Geiger et al., 1981). Indeed, the existence of vinculin at the $\mathrm{AChR}$ clusters has been demonstrated in rat myotubes (Bloch and Geiger, 1980). Thus, the polypeptide-coated beads may induce a change in the interaction between the actin filaments and the membrane and perhaps a localization of vinculin.

The particles seen in Figure 9 (inset) are similar in diameter and spacing to the large intramembranous particles at the postsynaptic membrane. Thus, they may represent structures related to the AChRs. The 3- to 5$\mathrm{nm}$ short filaments associated with these parlicles may represent structures which attach them to other organelles or to the cytoskeleton. These membrane particleassociated filaments also have been reported in the postsynaptic zone of the spherical cell in the anteroventral cochlear nucleus (Gulley and Reese, 1981).

The function of the actin filaments in relation to the formation of the postsynaptic membrane is not known. They could be involved in the formation and/or the stabilization of the AChR clusters. The association of bundles of actin filaments with the AChR clusters (this work) and their involvement in the development of myofibrils (Peng et al., 1981b) certainly indicate the heterogeneity of their functions in muscle cells.

Invaginations of the surface membrane. Another prominent specialization which develops at the beadmuscle contacts is the invaginations of the surface membrane. Although such deep invaginations are absent from well formed AChR clusters in these Xenopus myotomal cells both in vivo and in vitro (Kullberg et al., 1977; Peng and Nakajima, 1978; Peng et al., 1980; Weldon and Cohen, 1979), previous freeze-fracture and thin section studies have shown that they are prominent features of certain AChR clusters in culture (Peng et al., 1980; Weldon et al., 1981). The current study clearly shows that these surface invaginations are associated with AChR clusters, the basal lamina, and the cytoplasmic density. Besides the ultrastructural specializations reported here, Weldon et al. (1981) have reported recently that they also are associated with cholinesterase.

Infoldings of the postsynaptic membrane are a promi-

Figures 6 and 7. Correlation between light and electron microscopic observations. After an overnight co-culture with polyornithine beads, the culture shown in Figure 7 was labeled with R-BTX and the location of the beads and their induced AChR clusters was correlated with phase (Fig. $7 a$ ) and fluorescence (Fig. $7 b$ ) microscopy while the cell was still alive. Then the culture was processed for EM. Thin sections of this identified cell perpendicular to the original substrate can be correlated with the light micrographs to determine exactly the section plane. Figure 6 shows an EM section whose length and location are marked by the solid line segment in Figure $7 a$. This section went through four AChR cluster-positive bead-muscle contacts $(A$ to $D$ ) as well as a lipid droplet $(L)$ and the nucleus $(N u)$. Such correlation ensures us that the ultrastructural specializations associated with the beads are at sites of AChR clusters. Magnifications: Figure 6, $\times 3,150$; Figure 7, $\times 440$.

Figure 8. Cytoplasmic density associated with the membrane at the bead-muscle contact. The membrane shows a gentle convolution which separates the density into segments. $B$, bead. Magnification $\times 114,000$.

Figure 9. Thin filaments (arrowheads) associated with the cytoplasmic density. The plasma membrane at the bead-muscle contact was cut slightly tangentially. The patchiness of the density is also obvious in this micrograph. $B, \mathrm{Bead} ; M F$, myofibril; $M T$, microtubule. Inset, Particles associated with the membrane at the bead-muscle contact. They are associated with 3- to 5-nm whisks (arrows). Magnification: main figure, $\times 61,750$; inset, $\times 93,000$. 

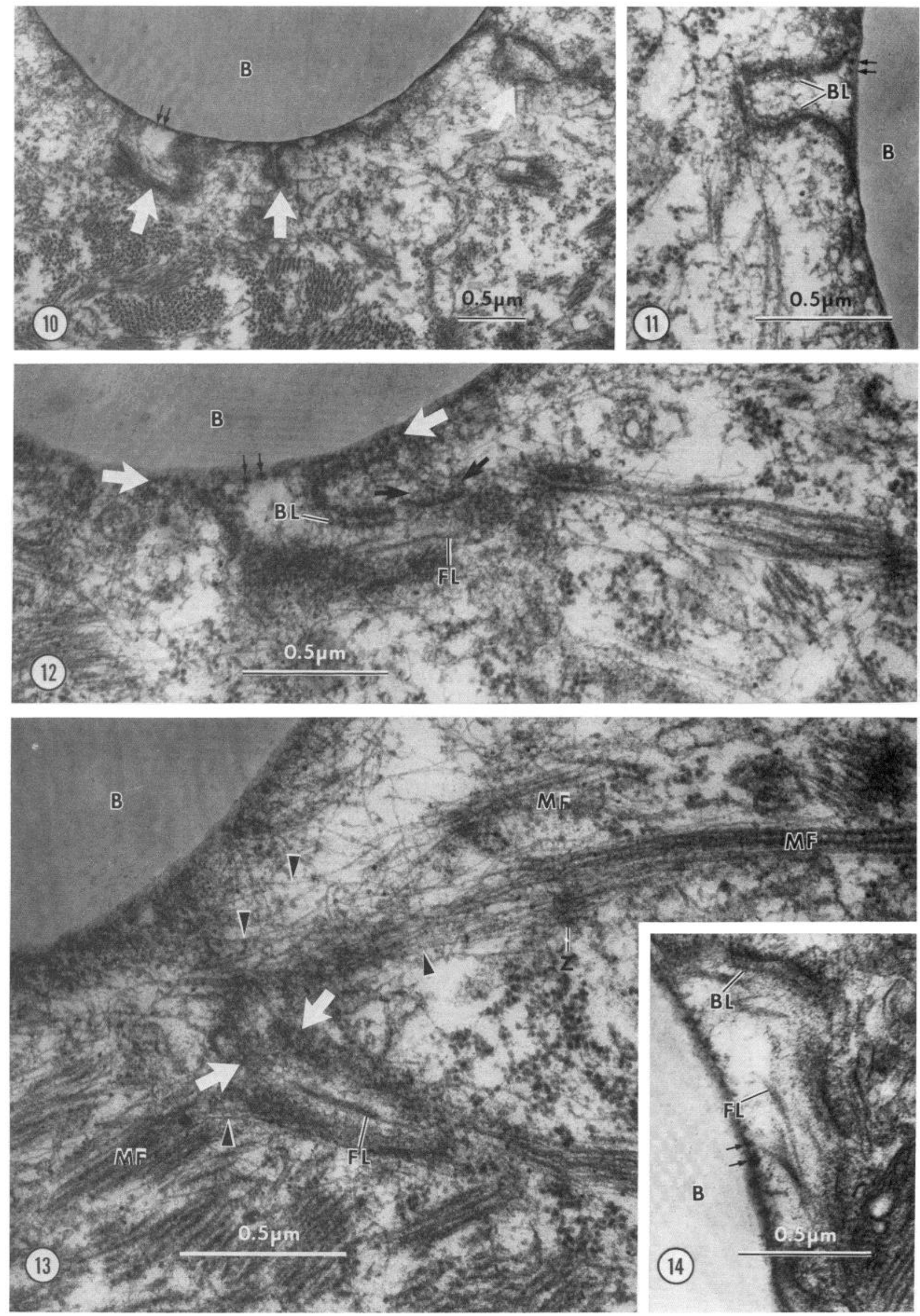

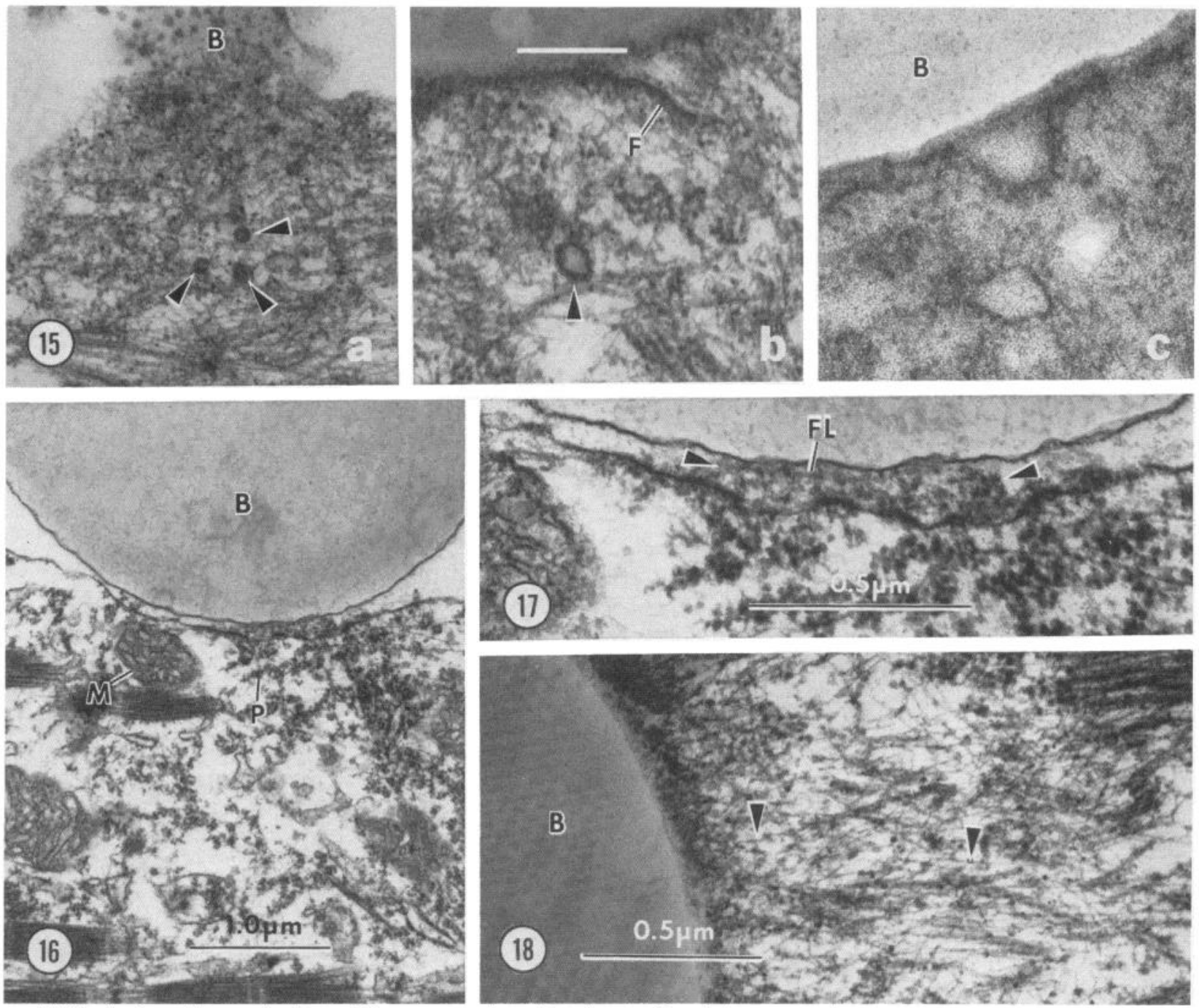

Figure 15. Coated vesicles and pits. $a$, Three coated vesicles (arrowheads) are seen in the vicinity of a bead-muscle contact. The bead $(B)$ was cut almost tangentially. $b$, A coated vesicle (arrowhead) clearly shows particles 13 to $15 \mathrm{~nm}$ in diameter on its cytoplasmic side. A portion of an invagination $(F)$ is seen just below the bead-muscle contact at the top. $c$, A coated pit at the bead-muscle contact. Magnification: $a, \times 28,200 ; b, \times 48,000 ; c, \times 113,200$. Scale bar, $0.5,0.3$, and $0.1 \mu \mathrm{m}$ for $a, b$ and $c$, respectively. Figures 16 and 17 . Contact between an uncoated bead and the muscle cell.

Figure 16. In contrast to polyornithine-coated beads, uncoated beads are smooth on their surface. The cleft is wider, although it also contains certain electron-dense material. The cytoplasm in the immediate vicinity is filled with the usual complement of organelles, including mitochondria $(M)$ and polysomes $(P)$. Magnification $\times 19,500$.

Figure 17. An enlarged portion of Figure 16. Note the cleft material consisting of both granular substance, which is distinct from the basal lamina shown in Figures 11, 12, and 14, and fibrils $(F L)$, which look similar to those seen in Figure 12. Magnification $\times 60,750$.

Figure 18. A 1-day-old polyornithine bead-muscle contact. The cytoplasmic density at the contact seems to be connected with a bundle of thin filaments (arrowheads). Magnification $\times 48,600$.

Figures 10 to 14 . Membrane invaginations at 1-day-old bead-muscle contacts.

Figure 10. Three invaginations (white arrows) are seen in this low power micrograph. The small arrows point to globules, presumably representing polyornithine molecules or certain medium components adsorbed to the surface of the bead $(B)$. Magnification $\times 24,500$.

Figure 11. Basal lamina $(B L)$ is associated with an invagination. Connections between the lamina and the membrane can be seen. Magnification $\times 49,200$.

Figure 12. The invagination (between white arrows) is lined with a cytoplasmic density. In the area between the black arrows, membrane-associated particulate structures (cf., Fig. 9, inset) can be seen. Besides the basal lamina, fibrils 10 to $15 \mathrm{~nm}$ in diameter $(F L)$ also exist within the invagination. The membrane in the lower part of the invagination was cut tangentially. Magnification $\times 52,600$.

Figure 13. An invagination was cut off from the surface so that it appears to be within the cytoplasm (white arrows). Thin filaments (arrowheads), which appear to extend from myofibrils $(M F)$, are contiguous with the density at the bead-muscle contact as well as with that at the invagination (lower left). $Z, \mathrm{Z}$ band. Magnification $\times 60,000$.

Figure 14. Both basal lamina $(B L)$ and 10- to 15-nm fibrils $(F L)$ are seen in this invagination. Globules of polyornithine molecules (small black arrows) are obvious. Magnification $\times 48,000$. 

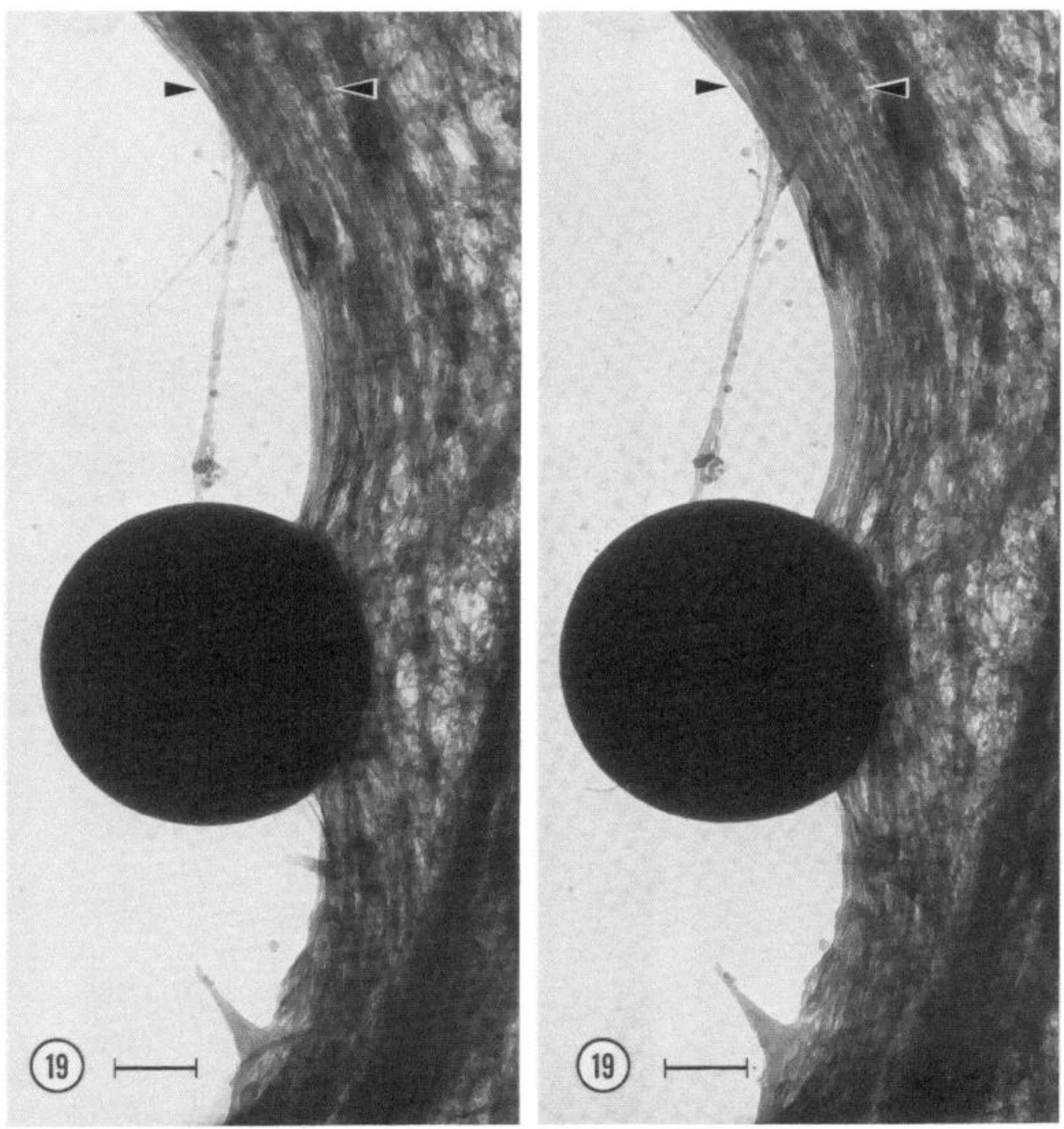

Figure 19. A polyornithine bead-muscle contact in whole mount (stereo pair). This $1.2-\mu \mathrm{m}$ bead makes a typical close contact with the edge of the cell. A bundle of thin filaments (between arrowheads), originally parallel to the cell margin, seems to attach to the membrane at the contact. This was photographed at a $20^{\circ}$ tilt angle. Magnification $\times 32,500$. Scale bar, $0.3 \mu \mathrm{m}$.

nent feature of the adult skeletal muscle (Couteaux and Dechavassine, 1968; Heuser, 1976), including adult Xenopus skeletal muscle (Peng and Nakajima, 1978). AChRs usually are concentrated at the apical portion of the fold and absent from the base of the fold (Fertuck and Salpeter, 1974). The structures in the Xenopus myotomal muscle cells which are probably homologous to these folds are the shallow grooves demarcating the AChR patches (Fig. 5; also Figs. 4 and 8 in Peng et al., 1980). AChRs also are absent from these grooves. Thus, the deep membrane invaginations reported here may be different from the folds observed in adult skeletal muscle.

The invaginations, however, bear a striking resemblance to the membrane infoldings at myotendinous junctions (Korneliussen, 1973; Nakao, 1976). In Xenopus myotomal muscle, the neuromuscular junction is located at the ends of the muscle cells in close proximity to the myotendinous junctions (Lewis and Hughes, 1960; Kullberg et al., 1977; also discussed in Weldon et al., 1981). Thus, our results indicate that polypeptide-coated latex beads can induce not only the postsynaptic specializations but also the myotendinous specializations in a man- ner similar to their development in vivo. Whether these two developmental events are interrelated in these myotomal muscle cells probably can be answered with the latex bead technique.

Our results also have shown that the basal lamina forms at the contacts between the muscle cell and the polyornithine-coated beads or the uncoated beads. However, the lamina material associated with these two types of contacts can be distinguished morphologically (Figs. 11 to 14 versus Fig. 17). This indicates that the basal lamina formed at the AChR clusters is different from that formed elsewhere. The 10- to 15 -nm fibrils shared by both types of contacts may represent a type of collagen fibrils.

Lateral movement of AChRs in the cell membrane. Our results indicate that pre-existing receptors are recruited to the bead-muscle contacts in the formation of new clusters. This agrees with previous studies that preexisting receptors are used in the formation of both nerve-free (Bloch, 1979) and nerve-induced (Anderson and Cohen, 1977) AChR clusters. Recent evidence indicates that diffuse AChRs are highly mobile in the plane 
of the plasma membrane (Axelrod et al., 1976; Poo, 1982). Thus, the pre-existing receptors can move laterally to the site of new cluster formation and become concentrated there. On the other hand, our data, as well as those of Bloch (1979), indicate that newly inserted receptors also participate in the formation of new clusters. Recent evidence indicates that a class of coated vesicles may be the vector for the insertion of new receptors (Rees, 1978; Rees et al., 1976; Bursztajn and Fischbach, 1979, 1980). Thus, the 100-nm coated vesicles reported here may be involved in this process. It is interesting to note that the particles associated with these vesicles are similar in dimension and projection into the cytoplasm (Fig. $15 b$ ) to the particles observed at the surface membrane (Fig. 9, inset). Whether these structures represent $\mathrm{AChRs}$ remains to be demonstrated. These vesicles seem to be different from the coated vesicles observed in many cells undergoing endocytosis. In the endocytic cell, the vesicles look like wheels with 7 -nm thin spokes emanating from the vesicular membrane in thin sections (Kanaseki and Kadota, 1969), whereas these structures are absent from the vesicles reported here.

Conclusion. In this paper, we have demonstrated that latex beads coated with positively charged polypeptide can trigger the formation of postsynaptic specializations in the absence of nerve. This work also suggests that several types of specializations are regulated coordinately. Many agents besides nerve can trigger the $\mathrm{AChR}$ clustering. However, we have been able to demonstrate the formation of a set of postsynaptic specializations in addition to AChR clusters at predictable positions on the muscle cell. Thus, the latex bead technique should be a more useful tool in the analysis of the cellular mechanisms involved in the formation of the postsynaptic membrane during synaptogenesis.

\section{References}

Anderson, M. J., and M. W. Cohen (1977) Nerve-induced and spontaneous redistribution of acetylcholine receptors on cultured muscle cells. J. Physiol. (Lond.) 268: 757-773.

Anderson, M. J., M. W. Cohen and E. Zorychta (1977) Effects of innervation on the distribution of acetylcholine receptors on cultured muscle cells. J. Physiol. (Lond.) 268: 731-756.

Axelrod, D., P. Ravdin, D. E. Koppel, J. Schlessinger, W. W. Webb, E. L. Elson, and T. R. Podleski (1976) Lateral motion of fluorescently labeled acetylcholine receptors in membranes of developing muscle fibers. Proc. Natl. Acad. Sci. U. S. A. 73: 4954-4958.

Bloch, R. J. (1979) Dispersal and reformation of acetylcholine receptor clusters of cultured rat myotubes treated with inhibitors of energy metabolism. J. Cell Biol. 82: 629-643.

Bloch, R. J., and B. Geiger (1980) The localization of acetylcholine receptor clusters in areas of cell-substrate contact in cultures of rat myotubes. Cell 21: 25-35.

Burden, S. J., P. B. Sargent, and U. J. McMahan (1979) Acetylcholine receptors in regenerating muscle accumulate at original synaptic sites in the absence of nerve. J. Cell. Biol. 82: $412-425$.

Burrage, T. G., and T. L. Lentz (1981) Ultrastructural characterization of surface specializations containing high-density acetylcholine receptors on embryonic chick myotubes in vivo and in vitro. Dev. Biol. 85: 267-286.

Burry, R. W. (1980) Formation of apparent presynaptic elements in response to poly-basic compounds. Brain Res. 184: 85-98.

Bursztajn, S., and G. D. Fischbach (1979) Coated vesicles in cultured myotubes contain acetylcholine receptors. Soc. Neurosci. Abstr. 5: 477 .

Bursztajn, S., and G. D. Fischbach (1980) Accumulation of coated vesicles bearing $\alpha \mathrm{BTX}$ binding sites in brain-treated myotubes. Soc. Neurosci. Abstr. 6: 358.

Cheng, P. -C., and M. -I. Lin (1981) Technique and apparatus for serial ultra-thin sectioning. Natl. Sci. Counc. Monthly, ROC 9: 15-22.

Christian, C. N., M. P. Daniels, H. Sugiyama, Z. Vogel, L. Jacques and P. G. Nelson (1978) A factor from neurons increases the number of acetylcholine receptor aggregates on cultured muscle cells. Proc. Natl. Acad. Sci. U. S. A. 75: 40114015.

Cohen, M. W., and P. R. Weldon (1980) Localization of acetylcholine receptors and synaptic ultrastructure at nerve-muscle contacts in culture: Dependence on nerve type. J. Cell Biol. 86: $388-401$

Cohen, S. A., and D. W. Pumplin (1979) Clusters of intramembrane particles associated with binding sites for $\alpha$-bungarotoxin in cultured chick myotubes. J. Cell Biol. 82: 494-516.

Couteaux, R., and P. Dechavssine (1968) Particularites structurales due sarcoplasme sous-neural. C. R. Acad. Sci. [D] (Paris) 266: 8-10.

Fertuck, H. C., and M. M. Salpeter (1974) Localization of acetylcholine receptor by ${ }^{125}$ I-labeled $\alpha$-bungarotoxin binding at mouse motor endplates. Proc. Natl. Acad. Sci. U. S. A. 71: 1376-1378.

Fischbach, G. D., and S. A. Cohen (1973) The distribution of acetylcholine sensitivity over uninnervated and innervated muscle fibers grown in cell culture. Dev. Biol. 31: 147-162.

Geiger, B. (1979) A $130 \mathrm{~K}$ protein from chicken gizzard: Its localization at the termini of microfilament bundles in cultured chicken cells. Cell 18: 193-205.

Geiger, B., A. H. Dutton, K. T. Tokuyasu, and S. J. Singer (1981) Immunoelectron microscope studies of membrane-microfilament interactions: Distribution of $\alpha$-actinin, tropomyosin, and vinculin in intestinal epithelial brush border and chicken gizzard smooth muscle cells. J. Cell Biol. 91: 614-628.

Gulley, R. L., and T. S. Reese (1981) Cytoskeletal organization at the postsynaptic complex. J. Cell Biol. 91: 298-302.

Hall, Z. W., B. W. Lubit; and J. H. Schwartz (1981) Cytoplasmic actin in postsynaptic structures at the neuromuscular junction. J. Cell. Biol. 90: 789-792.

Hamburger, V. (1960) A Manual of Experimental Embryology, University of Chicago Press, Chicago.

Heuser, J. E. (1976) Morphology of synaptic vesicle discharge and reformation at the frog neuromuscular junction. In Motor Innervation of Muscle, S. Thesleff, ed., pp. 51-115, Academic Press, New York.

Hirano, H. (1967) Ultrastructural study on the morphogenesis of the neuromuscular junction in the skeletal muscle of the chick. Z. Zellforsch. Mikrosk. Anat. 79: 198-208.

Hirokawa, N., and J. E. Heuser (1982) Internal and external differentiations of the postsynaptic membrane at the neuromuscular junction. J. Neurocytol. 11: 487-510.

Jessell, T. M., R. E. Siegel, and G. D. Fischbach (1979) Induction of acetylcholine receptors on cultured skeletal muscle by a factor extracted from brain and spinal cord. Proc. Natl. Acad. Sci. U. S. A. 76: 5397-5401.

Jones, K. W., and T. R. Elsdale (1963) The culture of small aggregates of amphibian embryonic cells in vitro. J. Embryol. Exp. Morphol. 11: 135-154.

Jones, R., and G. Vrbova (1974) Two factors responsible for the development of denervation hypersensitivity. J. Physiol. (Lond.) 236: 517-538.

Kanaseki, T., and K. Kadota (1969) The vesicle in a basket. J. Cell Biol. 42: 202-220.

Kelly, A. M., and S. J. Zachs (1969) The fine structure of motor endplate morphogenesis. J. Cell Biol. 42: 154-169.

Korneliussen, H. (1973) Ultrastructure of myotendinous junc- 
tions in Myxine and rat. Z. Anat. Entwicklungsgesch. 142: 91-101.

Kuffler, S. W., and D. Yoshikami (1975) The distribution of acetylcholine sensitivity at the postsynaptic membrane of vertebrate skeletal twitch muscles: Iontophoretic mapping in the micron range. J. Physiol. (Lond.) 244: 703-730.

Kullberg, R. W., T. L. Lentz, and M. W. Cohen (1977) Development of the myotomal neuromuscular junction in Xenopus laevis: An electrophysiological and fine-structural study. Dev. Biol. 60: 101-129.

Lewis, P. R., and A. F. W. Hughes (1960) Patterns of myoneural junctions and cholinesterase activity in the muscles of tadpoles of Xenopus laevis. Q. J. Microsc. Sci. 101: 55-67.

McMahan, U. J., J. R. Sanes, and L. M. Marshall (1978) Cholinesterase is associated with the basal lamina at the neuromuscular junction. Nature 271: 172-174.

Moody-Corbett, F., and M. W. Cohen (1979) Development of synaptic specializations on cultured non-innervated muscle cells at sites of contact with the culture dish. Soc. Neurosci. Abstr. 5: 486.

Moody-Corbett, F., and M. W. Cohen (1981) Localization of cholinesterase at sites of high acetylcholine receptor density on embryonic amphibian muscle cells cultured without nerve. J. Neurosci. 1: 596-605.

Nakajima, Y., Y. Kidokoro, and F. G. Klier (1980) The development of functional neuromuscular junctions in vitro. Dev. Biol. 77: 52-72.

Nakao, T. (1976) Some observations on the fine structure of the myotendinous junction in myotomal muscles of the tadpole tail. Cell Tissue Res. 166: 241-254.

Nieuwkoop, P. D., and J. Faber (1967) Normal Table of Xenopus laevis (Daudin), Ed. 2, North-Holland, Amsterdam.

Pappas, G. D., E. R. Peterson, E. B. Masurovsky, and S. M. Crain (1971) Electron microscopy of the in vitro development of mammalian motor endplates. Ann. N. Y. Acad. Sci. 183: 33-45.

Peng, H. B., and Y. Nakajima (1978) Membrane particle aggregates in innervated and noninnervated cultures of Xenopus embryonic muscle cells. Proc. Natl. Acad. Sci. U. S. A. 75: 500-504.

Peng, H. B., Y. Nakajima, and P. C. Bridgman (1980) Development of the postsynaptic membrane in Xenopus neuromuscular cultures observed by freeze-fracture and thin-section electron microscopy. Brain Res. 196: 11-31.

Peng, H. B., P. -C. Cheng, and P. W. Luther (1981a) Formation of $\mathrm{ACh}$ receptor clusters induced by positively charged latex beads. Nature 292: 831-834.

Peng, H. B., J. J. Wolosewick, and P. -C. Cheng (1981b) The development of myofibrils in cultured muscle cells: A wholemount and thin-section electron microscopic study. Dev. Biol. 88: 121-136.

Podleski, T. R., D. Axelrod, P. Ravdin, I. Greenberg, M. W. Johnson, and M. M. Salpeter (1978) Nerve extract induces increase and redistribution of acetylcholine receptors on cultured muscle cells. Proc. Natl. Acad. Sci. U. S. A. 75: 20352039.

Poo, M.-M. (1982) Rapid lateral diffusion of functional ACh receptors in embryonic muscle cell membrane. Nature 295: 332-334.

Ravdin, P., and D. Axelrod (1977) Fluorescent tetramethyl rhodamine derivatives of $\alpha$-bungarotoxin: Preparation, separation and characterization. Anal. Biochem. 80: 585-592.

Rees, R. P. (1978) Inclusion in coated vesicle membrane as the transport mechanism for acetylcholine receptor molecules in isolated cultured sympathetic neurons. J. Cell. Biol. 79: 99a.

Rees, R. P., M. B. Bunge, and R. P. Bunge (1976) Morphological changes in the neuritic growth cone and target neuron during synaptic junction development in culture. J. Cell Biol. 68: 240-263.

Rodriguez, J., and F. Deinhardt (1960) Preparation of semipermanent mounting medium for fluorescent antibody studies. Virology 12: 316-317.

Rubin, L. L., A. S. Gordon and U. J. McMahan (1980) Basal lamina fraction from the electric organ of Torpedo organizes acetylcholine receptors on cultured myotubes. Soc. Neurosci. Abstr. 6: 330.

Salisbury, J. L., J. S. Condeelis, and P. Satir (1980) Role of coated vesicles, microfilaments and calmodulin in receptormediated endocytosis by cultured B lymphoblastoid cells. J. Cell Biol. 87: 132-141.

Sanes, J. R., and Z. W. Hall (1979) Antibodies that bind specifically to synaptic sites on muscle fiber basal lamina. J. Cell. Biol. 83: 357-370.

Sytkowski, A. J., Z. Vogel and M. W. Nirenberg (1973) Development of acetylcholine receptor clusters on cultured muscle cells. Proc. Natl. Acad. Sci. U. S. A. 70: 270-274.

Teravainen, H. (1968) Development of the myoneural junction in the rat. Z. Zellforsch. Mikrosk. Anat. 87: 249-265.

Weinberg, C. B., J. R. Sanes, and Z. W. Hall (1981) Formation of neuromuscular junctions in adult rats. Dev. Biol. 84: 255266.

Weldon, P. R., and M. W. Cohen (1979) Development of synaptic ultrastructure at neuromuscular contacts in an amphibian cell culture system. J. Neurocytol. 8: 239-259.

Weldon, P. R., F. Moody-Corbett and M. W. Cohen (1981) Ultrastructure of sites of cholinesterase activity on amphibian embryonic muscle cells without nerve. Dev. Biol. 84: 341350.

Wolosewick, J. J., and K. R. Porter (1979) Preparation of cultured cells for electron microscopy. In Practical Tissue Culture Applications, K. Maramorsch and H. Hirumi, eds., pp. 59-85, Academic Press, New York.

Yee, A. G., G. D. Fischbach, and M. J. Karnovsky (1978) Clusters of intramembranous particles on cultured myotubes at sites that are highly sensitive to acetylcholine. Proc. Natl. Acad. Sci. U. S. A. 75: 3004-3008. 